Correction

\title{
Correction: Nguyen et al. Individual Sick Fir Tree (Abies mariesii) Identification in Insect Infested Forests by Means of UAV Images and Deep Learning. Remote Sens. $2021,13,260$
}

\author{
Ha Trang Nguyen ${ }^{1, *}$, Maximo Larry Lopez Caceres ${ }^{1}$, Koma Moritake $^{2}$, Sarah Kentsch ${ }^{1}$ (D), Hase Shu ${ }^{1}$ \\ and Yago Diez 2 \\ 1 Faculty of Agriculture, Yamagata University, Tsuruoka 997-8555, Japan; \\ larry@tds1.tr.yamagata-u.ac.jp (M.L.L.C.); sarah@tds1.tr.yamagata-u.ac.jp (S.K.); \\ s.hase@tds1.tr.yamagata-u.ac.jp (H.S.) \\ 2 Faculty of Science, Yamagata University, Yamagata 990-8560, Japan; s170291@st.yamagata-u.ac.jp (K.M.); \\ yago@sci.kj.yamagata-u.ac.jp (Y.D.) \\ * Correspondence: nguyen0005@tds1.tr.yamagata-u.ac.jp
}

check for updates

Citation: Nguyen, H.T.; Caceres, M.L.L.; Moritake, K.; Kentsch, S.; Shu, H.; Diez, Y. Correction: Nguyen et al. Individual Sick Fir Tree (Abies mariesii) Identification in Insect Infested

Forests by Means of UAV Images and Deep Learning. Remote Sens. 2021, 13, 260. Remote Sens. 2021, 13, 2100. https://doi.org/10.3390/rs13112100

Received: 23 March 2021

Accepted: 25 April 2021

Published: 27 May 2021

Publisher's Note: MDPI stays neutral with regard to jurisdictional claims in published maps and institutional affiliations.

Copyright: (c) 2021 by the authors. Licensee MDPI, Basel, Switzerland. This article is an open access article distributed under the terms and conditions of the Creative Commons Attribution (CC BY) license (https:// creativecommons.org/licenses/by/ $4.0 /)$.
The authors wish to make the following corrections to this paper [1].

On page 1, line 5, bark beetle's name "(Ips typographus)" should be "(Polygraphus proximus).

On page 10, line 8, the metric "Counting measure (cnt)" should be "Counting measure $(\text { cnt } \%)^{\prime \prime}$.

On page 10, lines 10-11, the sentence "Consequently, negative values indicate that the algorithm underestimated the number of trees while positive values indicate overestimation" should be "Consequently, negative values indicate that the algorithm overestimated the number of trees, while positive values indicate underestimation".

The authors would like to apologize for any inconvenience caused to the readers by these changes.

\section{Reference}

1. Nguyen, H.T.; Lopez Caceres, M.L.; Moritake, K.; Kentsch, S.; Shu, H.; Diez, Y. Individual Sick Fir Tree (Abies mariesii) Identification in Insect Infested Forests by Means of UAV Images and Deep Learning. Remote Sens. 2021, 13, 260. [CrossRef] 